\title{
Orbital IgG4 Related Disease (IgG4RD): Incidence and Accompanying Histological Features Using the Latest Consensus Criteria
}

\author{
Anita SY Chan ${ }^{1,2,3}$, Sunny Shen ${ }^{2,3}$, Audrey Looi Lee Geok ${ }^{2,3}$, Seah Lay Leng ${ }^{2,3}$, Leonard Tan Hwan Cheong ${ }^{1}$ and Issam Al Jajeh ${ }^{1 *}$ \\ ${ }^{1}$ Histopathology, Pathology Department, Singapore General Hospital, 20 College Road, Academia, Level, 10, Diagnostics Tower, Singapore \\ ${ }^{2}$ Singapore National Eye Centre, 11 Third Hospital Avenue, Singapore \\ ${ }^{3}$ Singapore Eye Research Institute, 11 Third Hospital Avenue, Singapore
}

\begin{abstract}
Purpose: Orbital Immunoglobulin 4 (IgG4) related disease (IgG4RD) is a fibro-inflammatory condition that mimics sclerosing orbital inflammatory disease (OID). The recently published IgG4RD consensus criteria included its defining histological features. Using the published criteria, this study aims to describe the frequency of orbital IgG4RD and its histological features in OID biopsies over a 1 year period.

Method: Thirty-seven consecutive orbital biopsies for OID over 1 year were prospectively examined for the features of fibrosis, inflammation, and vasculitis. Immunohistochemistry (IHC) evaluation was performed when significant fibrosis and/or lymphoplasmacytic inflammation ( $>25 \%$ of the biopsy section) was present.

Results: Ten of $37(27 \%)$ orbital biopsies showed significant fibrosis and/ or lymphoplasmacytic inflammation with the remaining cases showing only non-specific chronic inflammation or reactive lymphoid hyperplasia. Only 3 cases $(30 \%)$ fulfilled the IgG4RD consensus criteria. The histological patterns included sclerosing dacroadenitis, sclerosing xanthogranulomatous orbital inflammation, and eosinophilic angiocentric fibrosis. Storiform fibrosis was the most common histological feature present $(70 \%)$, followed by dense lymphoplasmacytic inflammation $(60 \%)$. When both are present, an almost 2-fold elevation of tissue IgG4 plasma cells and ratio above the diagnostic cut-off was detected. Xanthogranulomatous inflammation and eosinophilia were occasionally present.

Conclusions: Using the consensus criteria, IgG4RD was diagnosed in $30 \%$ of our orbital biopsies with significant fibrosis and/ or inflammation and $11 \%$ of all OID biopsied in 1 year. Although the storiform fibrosis and lymphplasmacytic inflammation was most commonly seen, associated eosinophilia and xanthogranulomatous inflammation may also be seen in IgG4RD.
\end{abstract}

Keywords: IgG4 related disease; Orbital inflammatory disease; Histopathology; Sclerosing orbital inflammation

\section{Introduction}

Immunoglobulin (Ig) G4 related disease (IgG4RD) is a multiorgan fibro-inflammatory condition that encompasses retroperitroneal fibrosis, autoimmune pancreatitis and orbital inflammatory disease (OID) $[1-3,4]$. It is characterized by a fibrosing mass-like lesion with dense lymphoplasmacytic infiltrate rich in IgG4 plasma cells on histology $[1-3,5]$. In the orbit, florid reactive lymphoid hyperplasia and sclerosing OID are common differential diagnoses which may mimic IgG4RD. The recently published IgG4RD consensus criteria included its defining histological features and preferred method for quantification of tissue IgG4 [5]. The three major histological features describe include (1) A dense lymphoplasmacytic infiltrate, (2) Storiform fibrosis, (3) Obliterative fibrosis and the other histological features include (A) Phlebitis without obliteration and (B) Increased eosinophilia [6]. In addition, the statement highlighted that the absolute count of IgG4 plasma cells was the preferred technique, and discouraged the use of "eyeballing" estimates of IgG4: IgG ratios advocating instead comparisons of the absolute counts of IgG4 and IgG cells via the use of photographic analysis or by microscopy. Prior to this, the lack of a diagnostic criteria had led to over- and under-diagnosis of this disease, especially in small biopsies. Using this criteria, our study aims to describe the frequency of orbital IgG4RD and the accompanying histological features in OID biopsies over a 1 year period.

\section{Methods}

Thirty-seven consecutive cases of orbital and lacrimal gland biopsies for OID at the Histopathology department, Singapore General
Hospital (SGH) and Singapore National Eye Center (SNEC) from January 2012-January 2013 were prospectively reviewed using our orbital inflammatory protocol where all biopsies were subjected to Hemotoxylin and Eosin (H\&E) and Masson Trichrome (MT) stains.

\section{Quantification of fibrosis and inflammation}

Percentage of fibrosis was calculated by the comparison of area of fibrosis highlighted by the MT stain with total area of tissue. The degree of inflammatory infiltrate was graded in similarly. Those with significant fibrosis and/ or inflammatory infiltrate (significant fibrosis or inflammation was defined as $>25 \%$ of the biopsy section) were subjected to immunohistochemical (IHC) analysis for CD138 positive plasma cells, tissue IgG and IgG4 in addition to routine diagnostic stains to exclude infections and lymphoma when warranted. The pattern of fibrosis and inflammation and the presence of vasculitis were recorded.

*Corresponding author: Issam Al Jajeh, Histopathology, Pathology Department, Singapore General Hospital, 20 College Road, Academia, Level 10, Diagnostics Tower, Singapore 169856, Tel: 65-6321-4875; Fax: 65-62276562; E-mail: issam.al.jajeh@sgh.com.sg

Received September 16, 2014; Accepted October 16, 2014; Published October 18, 2014

Citation: Chan ASY, Shen S, Geok ALL, Leng SL, Cheong LTH, et al. (2014) Orbital IgG4 Related Disease (IgG4RD): Incidence and Accompanying Histological Features Using the Latest Consensus Criteria. J Cytol Histol 5: 286. doi:10.4172/2157-7099.1000286

Copyright: (C) 2014 Chan ASY, et al. This is an open-access article distributed under the terms of the Creative Commons Attribution License, which permits unrestricted use, distribution, and reproduction in any medium, provided the original author and source are credited. 
Citation: Chan ASY, Shen S, Geok ALL, Leng SL, Cheong LTH, et al. (2014) Orbital IgG4 Related Disease (IgG4RD): Incidence and Accompanying Histological Features Using the Latest Consensus Criteria. J Cytol Histol 5: 286. doi:10.4172/2157-7099.1000286

\section{Quantification of tissue IgG4 and calculation of IgG4: IgG ratio}

Using consecutive sections, the numbers of absolute counts of CD138 positive IgG4 and IgG cells were counted in 3 separate high power fields $(\mathrm{x} 40)$ where inflammation was maximal. The mean number of IgG4 and IgG was then calculated, and the ratio of IgG4:IgG was determined based on the mean number of IgG4 and IgG. Exclusion criteria included the diagnoses of Granulomatosis with polyangitis (GPA, previously known as Wegener's granulomatosis), Sjogren's syndrome, adnexal lymphomas such as extranodal marginal lympoma and cases with neutrophilic infiltration, necrosis or granulomatous inflammation. The histological diagnosis of IgG4RD was highly suggestive when the at least 1 of the major histological feature of the consensus criteria (storifiorm fibrosis, dense lymphoplasmacytic inflammation and obliterative phlebitis) was present with elevated tissue IgG4 plasma cells as defined by the consensus criteria [6]. The diagnostic criteria for elevated tissue IgG4 included both the presence of: 1) CD138 positive IgG4 positive plasma cells $>50$ per high power field (hpf), and 2) Ratio of IgG4: $\operatorname{IgG}>40 \%$ as stated in the consensus criteria [6]. These confirmed cases were also reviewed clinically and radiologically for evidence of systemic IgG4RD.

\section{Statistical analysis}

All data were expressed as mean \pm SD.

\section{Results}

Ten of 37 (27\%) of our orbital biopsies showed features suggestive of sclerosing orbital inflammation or IgG4RD characterized by significant fibrosis and/ or lymphoplasmacytic inflammation. The remaining cases showed only non-specific chronic inflammation or reactive lymphoid hyperplasia. Using the histological consensus criteria, only 3 of these $(3 / 10,30 \%)$ cases fulfilled the morphological features and IgG4 IHC definition described above. The histological patterns included: 1) Sclerosing orbital inflammation or dacroadenitis (Figures 1A-1C and 2) Sclerosing orbital inflammation with xanthogranulomatous inflammation (Figures 2A-2C and 3) Eosinophilic angiocentric fibrosis (EAF) (Figures 3A-3C).

\section{Fibrosis/ Sclerosis}

Seven cases $(7 / 10,70 \%)$ showed obvious storiform (whorl-like type) fibrosis with hyalinization/ sclerosis (Figure 1B, 2C and 3C), occupying $\geq 50 \%$ area of the tissue section. The remaining 3 cases showed some degree of fibrosis varying from $25 \%$ to less than $50 \%$ of the biopsy area. (Table 1)

\section{Inflammation}

The predominant inflammatory infiltrate comprised of lymphocytes and plasma cells (Figures 1C, 2C and 3B) and was present in about 6/10 $(60 \%)$ cases. Thirty percent showed only lymphoplasmacytic infiltrate without significant fibrosis ( $<25 \%$ biopsy area), another $30 \%$ showed BOTH dense lymphoplasmacytic infiltrate with significant storiform fibrosis $(>50 \%)$ and the remaining $40 \%$ did not have significant inflammation but only storiform fibrosis as the main feature. The predominance of plasma cells was often only highlighted on CD138 IHC (Figures 1D, 2D and 3D) and was not always apparent on routine HE stain. Scattered eosinophils were noted in the background but was only significantly elevated in 1 case (Figure 3B). Xanthogranulomatous inflammation in the absence of other infectious or underlying etiology was also noted in another case (Figure 2B and Table 1).

\section{Vasculitis}

Active vasculitis and obliterative phlebitis was not seen in any of the cases. Perivenular fibrosis and perivascular "onion skinning" was present in all 10 cases suggestive of previous non-obliterative phlebitis. (Table 1)

\section{Tissue IgG4 plasma cell counts and IgG4: IgG ratio}

In the 3 cases with BOTH storiform fibrosis and dense

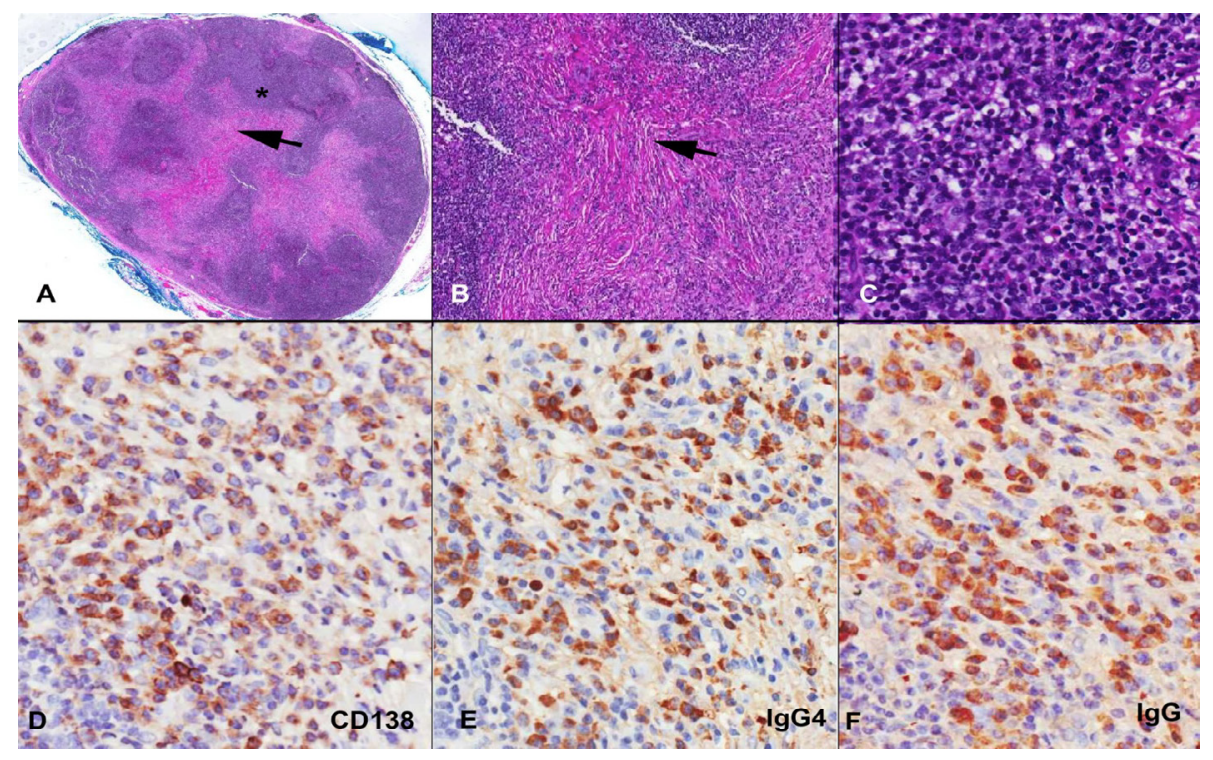

Figure 1: (A-F) Sclerosing dacryoadenitis form of IgG4RD. (A): Lacrimal gland biopsy, 2x Hematoxylin \& Eosin (HE) stain showing areas of fibrosis (arrow) and dense lymphoplasmacytic infitrate (asterix). (B): HE stain, 20x. Storiform fibrosis (arrow) characterized by thick eosinophilic collagen bands with a whorl-like appearance. (C): HE stain 20x. Dense lymphoplasmacytic infiltrate. (D \& E): CD138 and IgG4 immunohistochemistry (Peroxidase, 20x) showing increased tissue IgG4 CD138 positive plasma cells $\sim 134$ cell/ hpf. (E \& F): IgG4 and IgG immunohistochemistry (Peroxidase, 20x) showing increased IgG4: IgG ratio (90\%). 
Citation: Chan ASY, Shen S, Geok ALL, Leng SL, Cheong LTH, et al. (2014) Orbital IgG4 Related Disease (IgG4RD): Incidence and Accompanying Histological Features Using the Latest Consensus Criteria. J Cytol Histol 5: 286. doi:10.4172/2157-7099.1000286
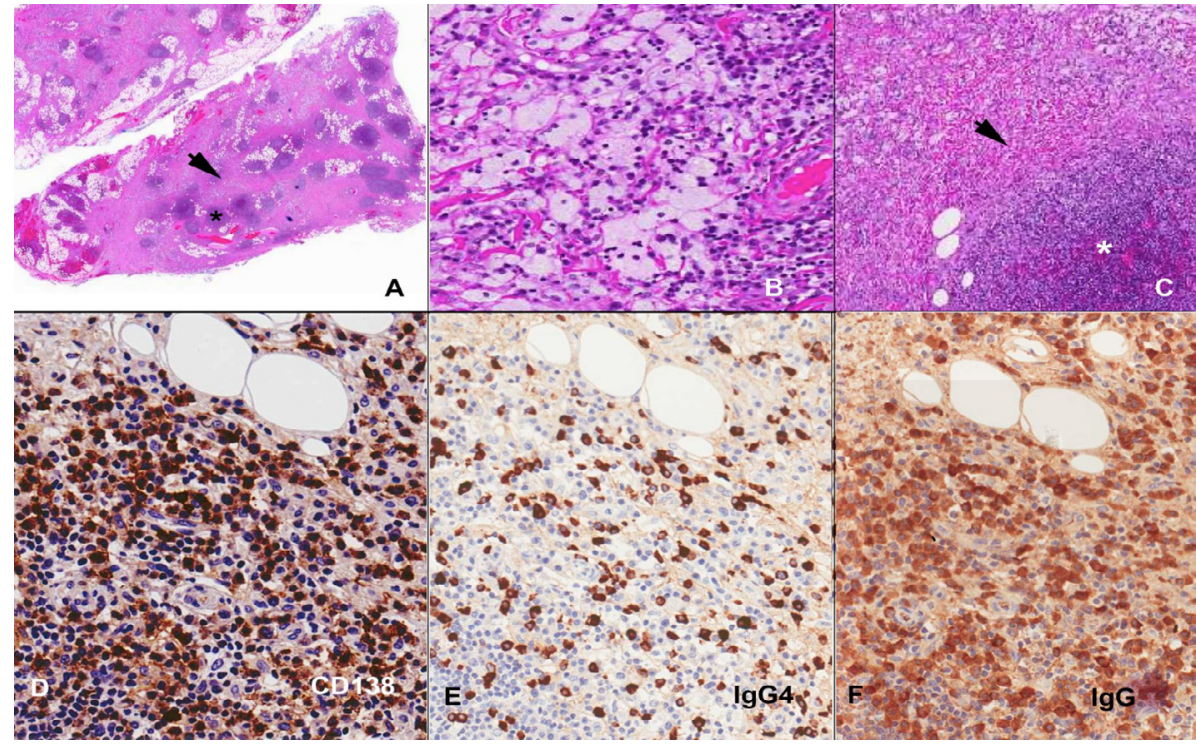

Figure 2: (A-F): Sclerosing xanthogranulomatous inflammation form of IgG4RD. (2A): Orbital biopsy, 2x Hematoxylin \& Eosin (HE) stain showing areas of fibrosis (arrow) and lymphoplasmacytic aggregates (asterix). (2B): HE stain, 40x Xanthogranulomatous inflammation characterized by foamy histiocytes. (2C): HE stain 10x. Dense lymphoplasmacytic infiltrate (asterix) and storiform fibrosis (arrow). (2D \& E): CD138 and IgG4 immunohistochemistry (Peroxidase, 20x) showing increased tissue IgG4 CD138 positive plasma cells $\sim 102$ cell/ hpf. (2E \& F): IgG4 and IgG immunohistochemistry (Peroxidase, 20x) showing increased IgG4: IgG ratio (75\%).

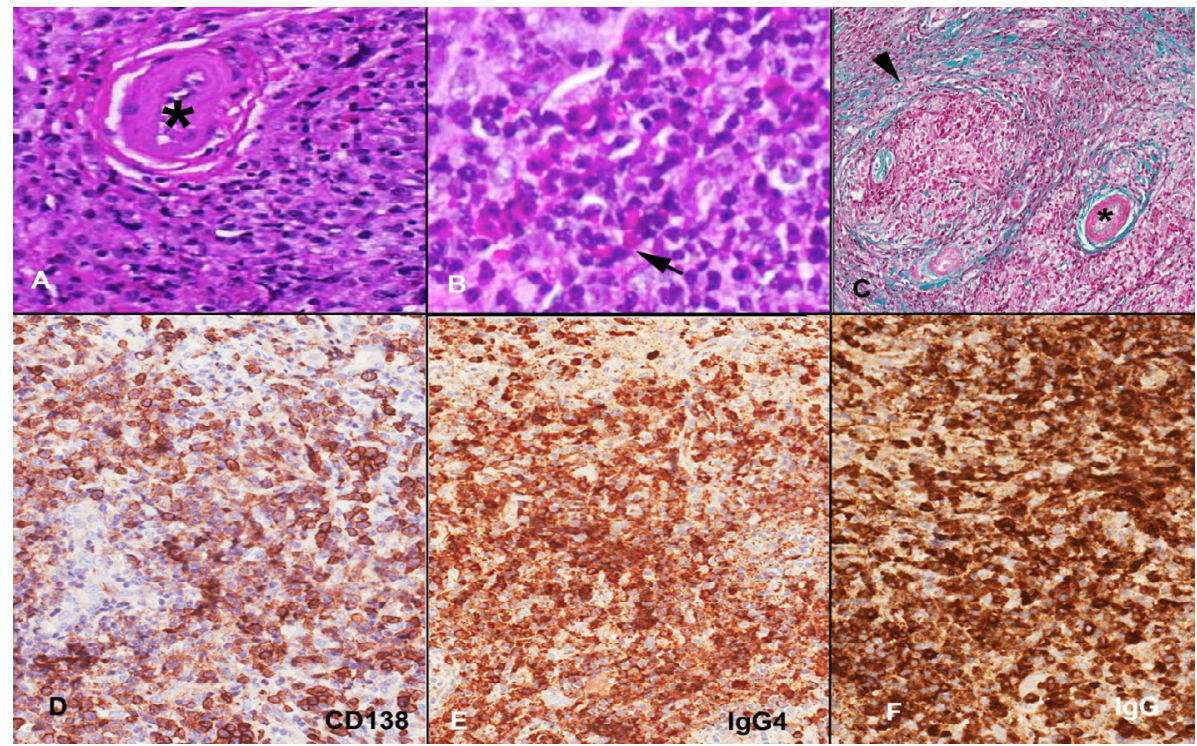

Figure 3: (A-F): Eosinophilic angiocentric fibrosis form of IgG4RD. (3A): "Onion skin" perivascular fibrosis (asterix), 2x Hematoxylin \& Eosin (HE) stain. (3B): HE stain, 40x. Marked eosinophil-rich (arrow) lymphoplasmacytic infiltrate. (3C): Masson Trichrome (MT) stain 4x. MT stain highlighting the perivascular fibrosis (asterix) and the background storiform fibrosis (arrowhead). (3D \& E): CD138 and IgG4 immunohistochemistry (Peroxidase, 20x) showing increased tissue IgG4 CD138 positive plasma cells $\sim 122$ cell/ hpf. (3E \& F): IgG4 and IgG immunohistochemistry (Peroxidase, 20x) showing increased lgG4: IgG ratio (80\%).

lymphoplasmacytic inflammation, a marked increased of tissue IgG4 plasma cells that fulfilled both criteria with the average of 119 (range: 102 to 134 cells) IgG4 positive plasma cells (identified using CD138, plasma cell marker)/ hpf and an IgG4: IgG ratio of $75-90 \%$ (Table 1).

In the remaining cases where only either storiform fibrosis (4 of 7) OR dense inflammation ( 3 of 7 ) was present, the IgG4 plasma cell count and IgG4: IgG ratio failed to meet the criteria with the average of 12 (range: 4 to 25 cells) IgG4 positive plasma cells/ hpf and an IgG4: IgG ratio of $10-20 \%$ (Table 1 ).

\section{Systemic review}

Our 3 cases of histologically diagnosed as IgG4RD had no prior history of IgG4RD, but were subsequently all found to have elevated serum IgG4 and other IgG4RD features: involvement of the parotid gland (Case 1, sclerosing dacroadenitis), autoimmune pancreatitis (Case 2, sclerosing xanthogranulomatous orbital inflammation) and retroperitoneal fibrosis (Case 3, EAF). 


\begin{tabular}{|c|c|c|c|c|c|c|c|c|c|c|c|c|c|}
\hline \multirow{2}{*}{ Cases } & \multicolumn{2}{|c|}{ Field $1(40 x)$} & \multicolumn{2}{|c|}{ Field $2(40 x)$} & \multicolumn{2}{|c|}{ Field $3(40 x)$} & \multicolumn{2}{|c|}{$\begin{array}{c}\text { Mean } \pm \\
\text { standard } \\
\text { deviation (SD)/ } \\
\text { 3hpf }\end{array}$} & & \multicolumn{4}{|c|}{ Histological criteria } \\
\hline & $\begin{array}{l}\text { No. of } \\
\text { lgG4 }\end{array}$ & $\begin{array}{l}\text { No. of } \\
\lg G\end{array}$ & $\begin{array}{l}\text { No. of } \\
\text { lgG4 }\end{array}$ & $\begin{array}{l}\text { No. of } \\
\text { lgG }\end{array}$ & $\begin{array}{l}\text { No. of } \\
\operatorname{lgG} 4\end{array}$ & $\begin{array}{l}\text { No. of } \\
\lg G\end{array}$ & $\begin{array}{l}\text { No. of } \\
\text { lgG4 }\end{array}$ & $\begin{array}{l}\text { No. of } \\
\lg G\end{array}$ & $\begin{array}{l}\lg 4: \lg G \\
\text { ratio }\end{array}$ & $\begin{array}{l}\text { Storiform } \\
\text { Fibrosis } \\
(>50 \%)\end{array}$ & $\begin{array}{l}\text { Lympho- } \\
\text { plasmacytic } \\
\text { inflammation } \\
(>50 \%)\end{array}$ & $\begin{array}{l}\text { Oblitera- } \\
\text { tive phle- } \\
\text { bitis }\end{array}$ & Other features \\
\hline $\begin{array}{l}\text { Case 1: Sclerosing } \\
\text { dacryoadenits }\end{array}$ & 134 & 148 & 145 & 160 & 123 & 136 & $\begin{array}{c}134 \pm \\
11\end{array}$ & $148 \pm 12$ & $90 \%$ & Yes & Yes & No & $\begin{array}{c}\text { Non-Obliterative } \\
\text { phlebitis }\end{array}$ \\
\hline $\begin{array}{l}\text { Case 2: Sclerosing } \\
\text { xanthogranulomatous } \\
\text { inflammation }\end{array}$ & 102 & 136 & 98 & 131 & 107 & 143 & $102 \pm 5$ & $137 \pm 6$ & $75 \%$ & Yes & Yes & No & $\begin{array}{c}\text { Xanthogranulomatous } \\
\text { inflammation } \\
\text { Non-Obliterative } \\
\text { phlebitis }\end{array}$ \\
\hline $\begin{array}{l}\text { Case 3: Eosinophilic } \\
\text { angiocentric fibrosis }\end{array}$ & 114 & 144 & 122 & 152 & 130 & 163 & $122 \pm 8$ & $153 \pm 10$ & $80 \%$ & Yes & Yes & No & $\begin{array}{l}\text { Eosinophilia Non- } \\
\text { Obliterative phlebitis }\end{array}$ \\
\hline $\begin{array}{l}\text { Case 4: Sclerosing } \\
\text { dacryoadenits }\end{array}$ & 4 & 50 & 4 & 38 & 4 & 32 & $4 \pm 0$ & $40 \pm 9$ & $20 \%$ & Yes & No & No & $\begin{array}{c}\text { Non-Obliterative } \\
\text { phlebitis }\end{array}$ \\
\hline $\begin{array}{l}\text { Case } 5 \text { : Chronic } \\
\text { dacryoadenits with reactive } \\
\text { lymphoid hyperplasia }\end{array}$ & 25 & 160 & 19 & 145 & 23 & 151 & $22 \pm 3$ & $152 \pm 8$ & $15 \%$ & No $(25-50 \%)$ & Yes & No & $\begin{array}{l}\text { Non-Obliterative } \\
\text { phlebitis }\end{array}$ \\
\hline $\begin{array}{l}\text { Case 6: Sclerosing } \\
\text { dacryoadenits }\end{array}$ & 11 & 60 & 9 & 75 & 15 & 85 & $11 \pm 3$ & $63 \pm 10$ & $18 \%$ & Yes & No & No & $\begin{array}{c}\text { Non-Obliterative } \\
\text { phlebitis }\end{array}$ \\
\hline $\begin{array}{l}\text { Case 7: Sclerosing orbital } \\
\text { inflammation }\end{array}$ & 15 & 75 & 11 & 88 & 21 & 82 & $16 \pm 5$ & $82 \pm 7$ & $20 \%$ & Yes & No & No & $\begin{array}{c}\text { Non-Obliterative } \\
\text { phlebitis }\end{array}$ \\
\hline $\begin{array}{l}\text { Case 8: Chronic } \\
\text { dacryoadenits with reactive } \\
\text { lymphoid hyperplasia }\end{array}$ & 8 & 80 & 12 & 76 & 6 & 72 & $9 \pm 3$ & $76 \pm 4$ & $12 \%$ & No $(25-50 \%)$ & Yes & No & $\begin{array}{c}\text { Non-Obliterative } \\
\text { phlebitis }\end{array}$ \\
\hline $\begin{array}{l}\text { Case 9: Sclerosing orbital } \\
\text { inflammation }\end{array}$ & 12 & 115 & 9 & 120 & 15 & 110 & $12 \pm 3$ & $115 \pm 5$ & $10 \%$ & Yes & No & No & $\begin{array}{c}\text { Non-Obliterative } \\
\text { phlebitis }\end{array}$ \\
\hline $\begin{array}{l}\text { Case 10: Chronic } \\
\text { dacryoadenits }\end{array}$ & 9 & 85 & 12 & 99 & 6 & 86 & $9 \pm 9$ & $90 \pm 8$ & $10 \%$ & No $(25-50 \%)$ & Yes & No & $\begin{array}{c}\text { Non-Obliterative } \\
\text { phlebitis }\end{array}$ \\
\hline
\end{tabular}

Table 1: Overall description of different histological criteria with different cases.

\section{Conclusions}

Rootman et al. first described an idiopathic sclerosing orbital inflammation which is clinically aggressive [7]. Orbital IgG4RD has renewed interest in sclerosing orbital inflammation and reports have suggested their shared histological features may represent a spectrum of IgG4RD $[4,8,9]$.

Using the IgG4RD consensus criteria, we found that almost $27 \%$ of our OID orbital biopsies shared overlapping features of sclerosing and IgG4RD making this criteria useful for differentiation of these entities since sclerosing OID is a more aggressive orbital inflammation requiring early immunosuppression therapy [7] in comparison to IgG4RD which is highly steroid sensitive, in addition to having systemic implications $[1,4,5,8]$. In our study, IgG4RD accounted for $11 \%$ of all our OID and up to $30 \%$ of our orbital inflammation with significant fibrosis and/ or inflammation. As IgG4RD overlaps with many other systemic AI disorders, it is a diagnosis of exclusion. Elevated tissue IgG4 is also present in Sjogren's syndrome and GPA related orbital inflammation and must be excluded prior the diagnosis of IgG4RD as in our series. [4,6] Of note, in our study, the orbital biopsy provided the first histological evidence of IgG4RD and it is important for the ophthalmologist to exclude systemic involvement.

The histological presentation of IgG4RD is variable from sclerosing dacroadenitis, to defined entities such as EAF, which recently has been suggested as IgG4RD $[9,11,12]$. Xanthogranulomatous inflammation has not been previously described in IgG4RD and extensive workup to exclude infection and other autoimmune disorders is necessary. Our patient with sclerosing xanthogranulomatous IgG4RD was subsequently found to have autoimmune pancreatitis and elevated serum IgG4RD. The association of xanthogranulomatous inflammation with elevated IgG4 plasma cells however does raise the issue of whether another xanthogranulomatous orbital inflammation, Adult onset xanthogranulomatous inflammation could represent IgG4RD as both share the association with asthma and elevated IgE, although more cases would have to be evaluated to confirm this observation.

In our study, the most common major histological feature seen for IgG4RD was storiform fibrosis $70 \%$, followed by dense lymphoplasmacytic infiltrate (60\%). The lack of storiform fibrosis in the lacrimal gland as described by the consensus group [6] was not reflected in our series as $70 \%$ of our cases presented with significant fibrosis. This discrepancy may represent the different stages of orbital inflammation at the time of biopsy, however, a larger series would be necessary to confirm this.

When both storiform fibrosis and lymphoplasmacytic infiltration were present, we noted a marked elevation of IgG4 plasma cells and the IgG4: IgG ratio which was consistently almost 2 -fold above the diagnostic criteria with over 100 IgG4positive plasma cells present and the IgG4: IgG ratio of $75-90 \%$ (Table 1). This correlates with the consensus group findings and others who report the number of IgG4 plasma cells in the lacrimal gland as typically in the 100s range (Table 1) $[6,10]$. This should be kept in mind when only a borderline number of IgG4 plasma cells are present in the biopsies to prevent over reporting. In such situation, it is necessary to exclude other autoimmune (AI) conditions since IgG4 plasma cells are not specific to IgG4RD and to correlate with the presence of other systemic IgG4RD features. Although borderline values of IgG4 plasma cells may represent the "early stage" of IgG4RD, long term follow up to determine the true IgG4 nature in repeat or other organ biopsies would be necessary to confirm such a suspicion in the absence of other clinical features. 
Citation: Chan ASY, Shen S, Geok ALL, Leng SL, Cheong LTH, et al. (2014) Orbital IgG4 Related Disease (IgG4RD): Incidence and Accompanying Histological Features Using the Latest Consensus Criteria. J Cytol Histol 5: 286. doi:10.4172/2157-7099.1000286

Page 5 of 5

Of the cases that did not meet the diagnostic criteria of IgG4RD, four cases had only significant fibrosis whilst 3 cases had predominantly inflammation without significant fibrosis and all lacked tissue IgG4 plasma cells (an average of 12 IgG4 plasma cells/hpf and an IgG4: IgG ratio $<25 \%$, (Table 1 ). The issue of whether the 4 cases with only significant "sclerosing" inflammation could represents a "burntout" fibrotic stage of IgG4RD rather than "idiopathic sclerosing inflammation" has yet to be resolved. However, without serum IgG4 elevation and other clinical evidence of IgG4 RD, it may be best to classify these cases as "sclerosing orbital inflammation with insufficient evidence for IgG4RD”.

In conclusion, orbital IgG4RD represents $11 \%$ of all our OID and $30 \%$ of those with significant sclerosis and dense lymphoplasmacytic infiltrate seen over 1 year. Tissue IgG4 levels is paramount to the diagnosis and both the number of IgG4 plasma cells and IgG4: IgG ratio must be assessed. Systemic review is a useful adjunct to exclude IgG4RD. Although storiform fibrosis and lymphplasmacytic inflammation is predominantly seen, the presence of eosinophils and xanthogranulomatous inflammation may also be present in orbital IgGRD.

\section{References}

1. Carruthers MN, Stone JH, Khosroshahi A (2012) The latest on IgG4-RD: a rapidly emerging disease. Curr Opin Rheumatol 24: 60-69.

2. Deshpande V (2012) The pathology of IgG4-related disease: critical issues and challenges. Semin Diagn Pathol 29: 191-196.
3. Deshpande V (2012) IgG4-related disease. Introduction. Semin Diagn Pathol 29: $175-176$.

4. Berry-Brincat A, Rose GE (2012) Idiopathic orbital inflammation: a new dimension with the discovery of immunoglobulin G4-related disease. Curr Opin Ophthalmol 23: 415-419.

5. Stone JH, Chan JK, Deshpande V, Okazaki K, Umehara H, et al. (2013) IgG4Related Disease. Int J Rheumatol 2013: 532612.

6. Deshpande V, Zen Y, Chan JK, Yi EE, Sato Y, et al. (2012) Consensus statement on the pathology of IgG4-related disease. Mod Pathol 25: 1181-1192.

7. Rootman J, McCarthy M, White V, Harris G, Kennerdell J (1994) Idiopathic sclerosing inflammation of the orbit. A distinct clinicopathologic entity. Ophthalmology 101: 570-584

8. Hagiya C, Tsuboi H, Yokosawa M, Hagiwara S, Hirota T, et al. (2014) Clinicopathological features of IgG4-related disease complicated with orbital involvement. Mod Rheumatol 24: 471-476.

9. Deshpande V, Khosroshahi A, Nielsen GP, Hamilos DL, Stone JH (2011) Eosinophilic angiocentric fibrosis is a form of IgG4-related systemic disease. Am J Surg Pathol 35: 701-706.

10. Cheuk W, Yuen HK, Chan JK (2007) Chronic sclerosing dacryoadenitis: part of the spectrum of IgG4-related Sclerosing disease? Am J Surg Pathol 31: 643645.

11. Azam M, Husen YA, Hasan SH (2010) Eosinophilic angiocentric fibrosis of orbit. Indian J Pathol Microbiol 53: 850-852.

12. Leibovitch I, James CL, Wormald PJ, Selva D (2006) Orbital eosinophilic angiocentric fibrosis case report and review of the literature. Ophthalmology 113: $148-152$. 